\title{
Troponin Testing in the Emergency Department Real world experience
}

Mohammed Al-Maskari, Mahmoud Al-Makhdami, Hatim Al-Lawati, Hafidh Al-Hadi, "Sunil K. Nadar

$$
\text { فحص مستوى التروبونين في قسم الطوارى }
$$

محمد المسكري، محمود المكدمي، حاتم اللواتي، حفيظ الهادي، سونيل نادر

ABSTRACT: Objectives: The aim of this study was to examine patterns of troponin testing in the emergency department of a large tertiary care hospital in Oman and to determine its effect on patient management, including length of hospital stay (LOS). Methods: This retrospective study analysed the medical records of all adult patients undergoing troponin testing in the emergency department of the Sultan Qaboos University Hospital, Muscat, Oman, during the month of July 2015. Patients who presented with an ST-elevation myocardial infarction were excluded. Results: A total of 4,845 patients attended the emergency department during the study period; of these, troponin tests were ordered for 588 patients. The majority of the patients had negative troponin test results (81.3\%). Chest pain, palpitations and breathlessness were the most common presenting complaints for those with positive troponin results. However, $41.8 \%$ of patients did not have any cardiac symptoms. Individuals with positive troponin tests had a significantly longer LOS compared to those with negative tests (mean: three versus one day; $P=0.001$ ). In total, only $28.2 \%$ of those with positive troponin test results had final diagnoses associated with a cardiac condition, such as heart failure, an acute coronary syndrome (ACS), atrial fibrillation or other types of arrhythmia. Conclusion: A positive troponin test was associated with increased LOS; however, only a small proportion of these patients had a final diagnosis associated with a cardiac condition. Guidelines should be provided to ensure that troponin testing is performed only in cases where an ACS is suspected.

Keywords: Emergency Department; Troponin; Cardiovascular Abnormality; Acute Coronary Syndrome; Length of Stay; Oman.

الملخص: الههدف: تهدف هذه الدراسة لدراسة نمط إجراء فحص التروبونين في قسم الطواري بمستشفى كبير في عمان يقدم الرعاية الصدية الصحية

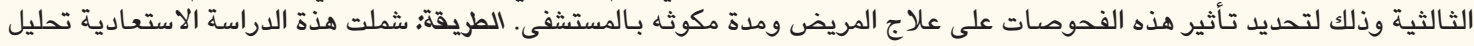

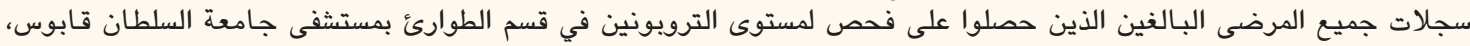

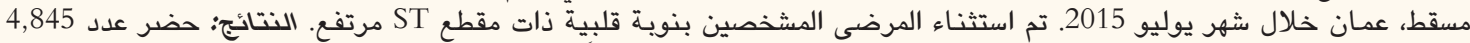

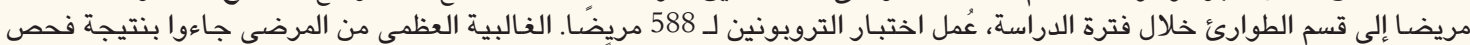

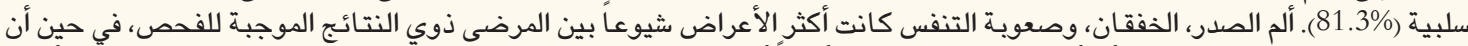

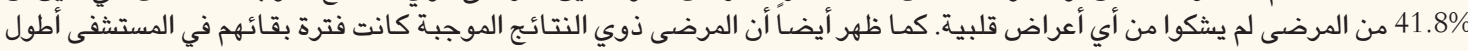

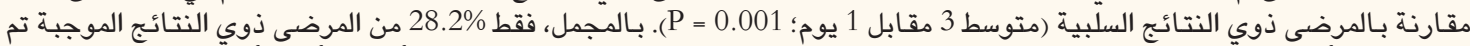

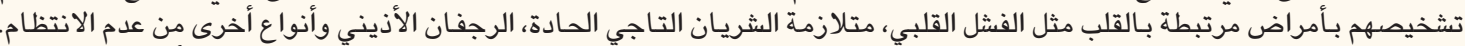

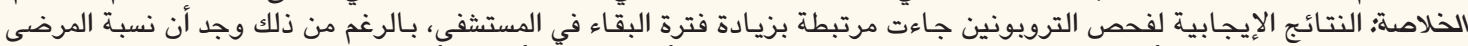

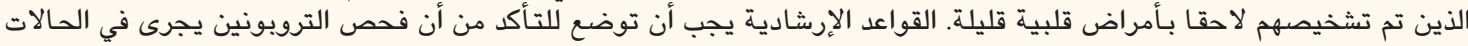
المتوقعة لمتلازمة الثريان التاجي الحادة فقط.

الكلمات المفتاحية؛ قسم الطوارئ؛ التروبونين؛ تشوه قلبي وعائي؛ متلازمة الثريان التاجي الحادة؛ فترة البقاء بالسستشفى؛ عمان.

\section{AdVANCES IN KNOWLEDGE}

Emergency department patients should not undergo troponin testing unless an acute coronary syndrome is suspected. In this study, a high degree of inappropriate troponin testing was observed.

\section{Application to Patient Care}

The findings of this study highlight the need for protocols to guide troponin testing as, unless indicated, it can lead to unnecessary investigations and delayed patient discharge. Accordingly, a thoroughly clinical evaluation should be conducted prior to a test request.

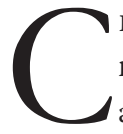

Hest PAIN IS ONE OF THE MOST COMMON reasons for emergency department (ED) attendance. ${ }^{1}$ As there are many causes of chest pain, the emergency physician has the responsibility of ruling out potentially life-threatening and serious conditions, such as a myocardial infarction (MI), aortic dissection or pulmonary embolism. Necessary diagnostic investigations include a thorough patient 
history and physical examination, chest X-rays, 12lead electrocardiography (ECG) and blood tests for myocardial injury biomarkers. Of these, the most widely used and extensively validated biomarkers for detecting cardiac cellular injury are cardiac troponins $\mathrm{T}$ and I (cTn-I) as they have a high sensitivity to and specificity for myocardial damage., ${ }^{2,3}$

However, because the troponin test is very sensitive, an inevitable number of false-positive results is to be expected. ${ }^{4}$ As the main reason for testing cardiac troponin is to rule out an acute coronary syndrome (ACS), it is thus essential that troponin is only checked in circumstances where the probability of ischaemic heart disease is high and an ACS is suspected, especially as indiscriminate troponin testing can lead to unnecessary investigations or a misdiagnosis. ${ }^{5,6}$ This study therefore aimed to review patterns of troponin testing among patients attending the ED of the Sultan Qaboos University Hospital (SQUH) in Muscat, Oman, and to examine whether initial troponin test results had an effect on patient management, especially length of hospital stay (LOS).

\section{Methods}

This retrospective study included all adult patients $\geq 18$ years old undergoing cTn-I testing following their admission to the ED of SQUH during July 2015. Patients who presented with a ST-elevation MI (STEMI) were excluded. The month of July was chosen at random for the study period. Patient data were obtained from the hospital's electronic records. Troponin levels were considered positive at $\geq 0.04 \mu \mathrm{g} / \mathrm{mL}$ and negative at $<0.04 \mu \mathrm{g} / \mathrm{mL}$, as per the reference levels recommended by the manufacturer of the assay kit (AccuTnl+3 Reagent Kit, Beckman Coulter Inc., Brea, California, USA). The presenting complaints of the patients were classified as either cardiac or non-cardiac, with presenting cardiac complaints including chest pain, palpitations, breathlessness and epigastric pain. Epigastric pain was included as a cardiac symptom as it is potentially indicative of an atypical presentation of angina; furthermore, it is often difficult to distinguish between epigastric and retrosternal discomfort. ${ }^{7}$ The final diagnosis of each patient was categorised as either cardiac or non-cardiac, with cardiac diagnoses including heart failure, an ACS, atrial fibrillation or other forms of arrhythmia.

All statistical analyses were performed using the Statistical Package for the Social Science (SPSS), Version 21.0 (IBM Corp., Armonk, New York, USA). A $P$ value of $<0.050$ was considered statistically significant. All categorical variables were presented as frequencies and percentages. Means and standard deviations were used to describe continuous normally distributed variables, while non-normally distributed variables were described as medians and interquartile ranges. A Chi-squared test was used to compare categorical variables between groups and a t-test was used to compare mean ages. A Mann-Whitney test was used to compare associations with LOS.

Ethical approval for this study was obtained from the Medical Ethics \& Research Committee of the College of Medicine \& Health Sciences, Sultan Qaboos University (MREC \#1122).

\section{Results}

During the study period, a total of 4,845 patients attended the ED of SQUH. Of these, 599 adult patients underwent cTn-I testing as part of their evaluation; however, 11 patients with STEMIs were excluded from the analysis. Accordingly, a total of 588 patients underwent 681 troponin tests. The mean age of the participants was $56.6 \pm 16.7$ years and $53.9 \%$ were male. A total of 110 (18.7\%) and 478 (81.3\%) patients had positive and negative initial troponin results,

Table 1: Demographic and clinical characteristics of emergency department patients undergoing troponin testing at the Sultan Qaboos University Hospital, Muscat, Oman $(\mathrm{N}=588)$

\begin{tabular}{|c|c|c|c|}
\hline \multirow[t]{2}{*}{ Characteristic } & \multicolumn{2}{|c|}{ n (\%) } & \multirow{2}{*}{$\begin{array}{c}P \\
\text { value }^{*}\end{array}$} \\
\hline & $\begin{array}{l}\text { Positive } \\
\text { troponin } \\
\text { findings } \\
(\mathbf{n}=110)\end{array}$ & $\begin{array}{l}\text { Negative } \\
\text { troponin } \\
\text { findings } \\
(\mathrm{n}=478)\end{array}$ & \\
\hline \multicolumn{4}{|l|}{ Gender } \\
\hline Male & $66(60.0)$ & $251(52.5)$ & \multirow{2}{*}{0.094} \\
\hline Female & $44(40.0)$ & $227(47.5)$ & \\
\hline \multicolumn{4}{|l|}{ Age } \\
\hline Mean \pm SD & $61.6 \pm 15.9$ & $55.5 \pm 16.8$ & $0.001^{\dagger}$ \\
\hline \multicolumn{4}{|l|}{ Comorbidities $^{\ddagger}$} \\
\hline Stroke & $8(7.3)$ & $12(2.5)$ & 0.020 \\
\hline CABG & $6(5.5)$ & $27(5.6)$ & 0.574 \\
\hline PCI & $11(10.0)$ & $30(6.3)$ & 0.123 \\
\hline Renal failure & $8(7.3)$ & $9(1.9)$ & 0.007 \\
\hline MI & $9(8.2)$ & $11(2.3)$ & 0.006 \\
\hline HTN & $56(50.9)$ & $215(45.0)$ & 0.158 \\
\hline Diabetes & 40 (36.4) & $170(35.6)$ & 0.484 \\
\hline \multicolumn{4}{|c|}{$\begin{array}{l}S D=\text { standard deviation; } C A B G=\text { coronary artery bypass graf } \\
P C I=\text { percutaneous coronary intervention; } M I=\text { myocardial } \\
\text { infarction; } H T N=\text { hypertension. }\end{array}$} \\
\hline $\begin{array}{l}\text { Calculated using a } \\
\text {-test. }{ }^{\ddagger} \text { Percentages } d \\
\text { lad more than one } c\end{array}$ & $\begin{array}{l}\text { quared test. } \\
\text { t add up to } 10 \\
\text { rbidity. }\end{array}$ & $\begin{array}{l}\text { ulated using } \\
\text { s patients me }\end{array}$ & $\begin{array}{l}\text { tudent's } \\
\text { have }\end{array}$ \\
\hline
\end{tabular}


Table 2: Presenting complaints among emergency department patients undergoing troponin testing at the Sultan Qaboos University Hospital, Muscat, Oman $(\mathrm{N}=588)$

\begin{tabular}{|c|c|c|c|}
\hline \multirow[t]{2}{*}{ Complaint } & \multicolumn{2}{|c|}{ n (\%) } & \multirow{2}{*}{$\begin{array}{c}P \\
\text { value }\end{array}$} \\
\hline & $\begin{array}{l}\text { Positive } \\
\text { troponin } \\
\text { findings } \\
(\mathrm{n}=110)\end{array}$ & $\begin{array}{l}\text { Negative } \\
\text { troponin } \\
\text { findings } \\
(\mathrm{n}=478)\end{array}$ & \\
\hline Chest pain & $20(14.8)$ & $115(85.2)$ & 0.001 \\
\hline Breathlessness & 35 (29.7) & $83(70.3)$ & 0.001 \\
\hline Palpitations & $5(33.3)$ & $10(66.7)$ & 0.001 \\
\hline Epigastric pain & $5(6.8)$ & $69(93.2)$ & 0.001 \\
\hline $\begin{array}{l}\text { Non-cardiac } \\
\text { complaints }\end{array}$ & $45(18.3)$ & $201(81.7)$ & 0.001 \\
\hline
\end{tabular}

Table 3: Management and length of stay of emergency department patients undergoing troponin testing at the Sultan Qaboos University Hospital, Muscat, Oman $(\mathrm{N}=588)$

\begin{tabular}{|c|c|c|c|}
\hline \multirow[t]{2}{*}{ Management } & \multicolumn{2}{|c|}{ n (\%) } & \multirow{2}{*}{$\begin{array}{c}P \\
\text { value }\end{array}$} \\
\hline & $\begin{array}{l}\text { Positive } \\
\text { troponin } \\
\text { findings } \\
(\mathrm{n}=110)\end{array}$ & $\begin{array}{l}\text { Negative } \\
\text { troponin } \\
\text { findings } \\
(n=478)\end{array}$ & \\
\hline Treated as ACS & $10(9.1)$ & $7(1.5)$ & $<0.001$ \\
\hline Angiography & $10(9.1)$ & $4(0.8)$ & $<0.001$ \\
\hline $\begin{array}{l}\text { Referred to a } \\
\text { cardiologist }\end{array}$ & $33(30.0)$ & $31(6.5)$ & $<0.001$ \\
\hline $\begin{array}{l}\text { Initial troponin } \\
\text { test only }\end{array}$ & $71(64.5)$ & $424(88.7)$ & $<0.001$ \\
\hline $\begin{array}{l}\text { At least one } \\
\text { repeat troponin } \\
\text { test }\end{array}$ & $39(35.5)$ & $54(11.3)$ & \\
\hline $\begin{array}{l}\text { Median LOS in } \\
\text { days (IQR) }\end{array}$ & $3(1-8)$ & $1(1-2)$ & 0.001 \\
\hline
\end{tabular}

ACS = acute coronary syndrome; $L O S=$ length of hospital stay; $I Q R=$ interquartile range.

Table 4: Final diagnoses of emergency department patients undergoing troponin testing at the Sultan Qaboos University Hospital, Muscat, Oman ( $\mathrm{N}=588)$

\begin{tabular}{|c|c|c|c|}
\hline \multirow[t]{2}{*}{ Final diagnosis } & \multicolumn{2}{|c|}{ n (\%) } & \multirow[t]{2}{*}{$P$ value ${ }^{*}$} \\
\hline & $\begin{array}{c}\text { Positive } \\
\text { troponin } \\
\text { findings } \\
(\mathrm{n}=110)\end{array}$ & $\begin{array}{c}\text { Negative } \\
\text { troponin } \\
\text { findings } \\
(\mathrm{n}=478)\end{array}$ & \\
\hline $\operatorname{Cardiac}^{\dagger}$ & $31(28.2)$ & $66(13.8)$ & \multirow[t]{2}{*}{$<0.001$} \\
\hline Non-cardiac & 79 (71.8) & $412(86.2)$ & \\
\hline
\end{tabular}

Table 5: Correlations between presenting complaints and final diagnoses among emergency department patients undergoing troponin testing at the Sultan Qaboos University Hospital, Muscat, Oman ( $\mathrm{N}=588)$

\begin{tabular}{|c|c|c|c|}
\hline \multirow{2}{*}{$\begin{array}{l}\text { Presenting } \\
\text { complaint }\end{array}$} & \multicolumn{2}{|c|}{ n (\%) } & \multirow{2}{*}{$\begin{array}{c}P \\
\text { value }\end{array}$} \\
\hline & $\begin{array}{c}\text { Cardiac } \\
\text { diagnoses* } \\
(\mathbf{n}=97)\end{array}$ & $\begin{array}{l}\text { Non-cardiac } \\
\text { diagnoses }(\mathrm{n} \\
=491)\end{array}$ & \\
\hline Chest pain & 35 (36.1) & $100(20.4)$ & $<0.001$ \\
\hline Breathlessness & $27(27.8)$ & $91(18.5)$ & $<0.001$ \\
\hline Palpitations & $5(5.2)$ & $10(2.0)$ & $<0.001$ \\
\hline Epigastric pain & $9(9.3)$ & $65(13.2)$ & $<0.001$ \\
\hline $\begin{array}{l}\text { Non-cardiac } \\
\text { symptoms }\end{array}$ & 21 (21.6) & $225(45.8)$ & $<0.001$ \\
\hline
\end{tabular}

"Including heart failure, an acute coronary syndrome, atrial fibrillation or other forms of arrhythmia.

respectively. Patients with positive troponin results were significantly older and more likely to have renal failure and MIs as comorbidities ( $P<0.050$ each). However, there was no association between elevated troponin results and coronary artery bypass grafting, percutaneous coronary interventions, hypertension or diabetes $(P>0.050)$ [Table 1$]$.

A total of 342 patients (58.1\%) presented with cardiac symptoms. Of these, chest pain was the most frequent ( $\mathrm{n}=135 ; 39.5 \%$ ), followed by breathlessness $(\mathrm{n}=118 ; 34.5 \%)$, epigastric pain $(\mathrm{n}=74 ; 21.6 \%)$ and palpitations $(\mathrm{n}=15 ; 4.4 \%)$. Interestingly, a large proportion of the patients $(n=246 ; 41.8 \%)$ did not present with any cardiac symptoms. Overall, only 65 (19.0\%) of those with cardiac symptoms had initial positive troponin test results, including $6.8 \%$ with epigastric pain. In addition, $18.3 \%$ of patients with non-cardiac symptoms also had raised troponin levels [Table 2].

In terms of management, 494 patients (84.0\%) did not have a repeat troponin test and 93 (15.8\%) underwent at least one repeat troponin test. Of those with initial positive troponin findings, 39 (35.5\%) underwent multiple repeat troponin tests as compared to $54(11.3 \%)$ with initial negative results. Only 33 (30.0\%) and 10 (9.1\%) patients with positive troponin results were referred to a cardiologist or underwent ACS management, respectively. All 10 of these ACS patients received an angiogram, of which four were normal. Of those with initial negative troponin results, 31 (6.5\%) were referred to a cardiologist, seven (1.5\%) underwent ACS management and four (0.8\%) had an angiogram, of which two were normal. Patients with 
positive troponin test results had a significantly greater LOS compared to those with negative troponin findings (mean: one versus three days; $P<0.050$ ) [Table 3].

A total of 97 patients (16.5\%) had a final diagnosis related to a cardiac condition, consisting of 31 patients (32.0\%) with positive troponin tests and 66 (13.8\%) with negative results [Table 4]. Specifically, six patients $(5.5 \%)$ with positive troponin test results and two $(0.4 \%)$ with negative findings were diagnosed with ACS. Overall, 76 (22.2\%) of patients with cardiac symptoms had a final cardiac diagnosis, including nine patients with epigastric pain [Table 5]. While a small proportion ( $\mathrm{n}=21 ; 8.5 \%$ ) of those patients presenting with non-cardiac complaints also had a cardiac diagnosis, most of these cases did not have an ACS.

\section{Discussion}

To the best of the authors' knowledge, this study is the first of its kind in the region to study the pattern of troponin testing in the ED of a large tertiary care centre. While the results indicated that cardiac troponin testing was performed mainly for patients with chest pain or in cases where an ACS was suspected, it was also occasionally requested for patients with non-cardiac-related symptoms. It is possible that the attending doctor in these cases requested troponin testing because they felt that the patient's presentation might be the result of an atypical manifestation of an ACS. Moreover, not all of the patients with positive troponin results in the current study were treated for an ACS, while a small number of patients with negative troponin results underwent ACS management based on their clinical presentation. This finding is in keeping with the guidelines of the European Society of Cardiology which specify that while troponin testing has a role in diagnosing a MI, a negative test does not always rule out other forms of ACS, such as unstable angina. ${ }^{8}$

Although troponin tests are widely available, not all hospitals have clear guidelines or protocols as to when a troponin test should be requested, which can inadvertently lead to the inappropriate use of this diagnostic investigation. ${ }^{5,6,9}$ While troponin tests are mainly used to diagnose an ACS, troponin levels can also be elevated in other cardiac conditions such as heart failure, tachyarrhythmias and post-cardiac arrest and direct current cardioversion as well as noncardiac conditions such as cerebrovascular accidents, head injuries, sepsis and pulmonary emboli. ${ }^{2-4}$ In these circumstances, a troponin test should only be performed if there is strong suspicion of an ACS—such as prior chest pain or ECG changes - as a positive result can be misleading. ${ }^{5,6}$ Interestingly, although 97 patients in the current study had a final cardiac-related diagnosis, only eight of these patients (8.2\%) were diagnosed with an ACS. This number is relatively low and might reflect the short study period. In addition, there may have been a high incidence of type 2 MIs (i.e. infarctions due to demand-supply mismatch rather than plaque rupture), which are often overlooked. ${ }^{10,11}$ Unfortunately, patients with STEMIs were not included in the current analysis and it was beyond the scope of this study to examine the incidence of type 2 MIs.

As expected, patients with positive troponin test results in the present study had a significantly longer LOS than those with negative findings. These patients were also significantly more likely to be treated for ACS, be referred to a cardiologist and undergo angiography. However, only $30.0 \%$ of patients with positive troponin results were referred to cardiologists; it is likely that the remaining $70.0 \%$ of patients were not considered to have a significant cardiac condition and were therefore not referred. In these cases, it is unclear why the troponin test was requested if such patients were not subsequently referred to a cardiologist despite their raised troponin levels. This finding may perhaps reflect the routine ordering of blood tests rather than requests made based on the patient's clinical presentation. Rehmani et al. similarly showed that $62.2 \%$ of blood tests requested from an ED at a large tertiary centre were considered inappropriate and that only $3.8 \%$ influenced patient management. ${ }^{12}$ Along the same lines, only $6.5 \%$ of patients with negative troponin findings in the current study were referred to a cardiologist although $13.8 \%$ had a final cardiacrelated diagnosis. This apparent discrepancy could be due to the fact that cardiac diagnoses included atrial fibrillation, arrhythmias and heart failure. As such, some patients may have presented to the ED with noncardiac symptoms but nevertheless received a cardiac diagnosis; for example, patients with coexisting atrial fibrillation may have received a cardiac diagnosis despite this not being the main reason for their attendance at the ED. A final diagnosis of an ACS was only made in a very small percentage of patients.

If an ACS is suspected and the initial troponin test result is negative, it is recommended that a repeat test be performed within six hours to completely rule out MIs and improve diagnostic accuracy. ${ }^{3,13}$ However, in the current sample, only a small number of patients underwent a second test and this proportion was even lower among those with an initial negative result. Research from other centres also indicates that these recommendations are not being followed. ${ }^{14,15}$ On the whole, the results of the current study confirmed those of similar studies conducted in other parts of the world. ${ }^{16,17}$ Such findings highlight the need for proper 
ED guidelines and protocols for troponin test requests. Triage nurses or physicians often request a wide array of blood tests while the patient is waiting to be seen by a doctor. ${ }^{18,19}$ Although these measures may help reduce patient wait times, it often results in unnecessary tests being ordered..$^{11,20,21}$ For economic reasons, it is prudent to limit such requests for unnecessary tests, in turn reducing unnecessary hospital stays and admissions. ${ }^{6}$

This study was subject to certain limitations due to its retrospective nature and the method of data collection using patient records. The cTn-I tests were requested by various ED doctors or triage nurses without standard protocols to guide requests for troponin testing or to screen for an ACS or myocardial injuries or infarctions. In addition, patients with negative cTn-I results were not followed up during their subsequent stay in the ED or hospital. The final diagnosis of a cardiac or non-cardiac abnormality was based solely on documentation from the initial ED visit. Similarly, final cardiac diagnoses were not subcategorised according to the specific condition as this was beyond the scope of this study; the focus of the analysis lay in determining the pattern of cTn-I test requests and not in studying the prevalence of individual cardiac conditions. Moreover, the sample size of the study was small due to the short study period. Finally, a major limitation of this study was the unavailability of ECG data for most patients.

\section{Conclusion}

In the current study, a large number of patients attending the ED were found to have undergone troponin testing despite presenting without cardiacrelated symptoms. Moreover, only a small proportion of patients with initial positive troponin test results received a final cardiac-related diagnosis upon discharge. Such unnecessary testing may lead to increased LOS and unnecessary referrals to the cardiology department. Hospital protocols regarding the appropriate use of troponin testing are therefore needed to guide emergency physicians and triage nurses.

\section{ACKNOWLEDGEMENTS}

The authors wish to thank the ED staff at SQUH for their cooperation during this study and for their help during the data collection process.

\section{CONFLICT OF INTEREST}

The authors declare no conflicts of interest.

\section{FUNDING}

No funding was received for this study.

\section{References}

1. Pitts SR, Niska RW, Xu J, Burt CW. National Hospital Ambulatory Medical Care Survey: 2006 emergency department summary. Natl Health Stat Report 2008:1-38.

2. Babuin L, Jaffe AS. Troponin: The biomarker of choice for the detection of cardiac injury. CMAJ 2005; 173:1191-202. doi: 10.1503/cmaj/051291.

3. Newby LK, Jesse RL, Babb JD, Christenson RH, De Fer TM, Diamond GA, et al. ACCF 2012 expert consensus document on practical clinical considerations in the interpretation of troponin elevations: A report of the American College of Cardiology Foundation Task Force on Clinical Expert Consensus Documents. J Am Coll Cardiol 2012; 60:2427-63. doi: 10.1016/j.jacc.2012.08.969.

4. Sandoval Y, Smith SW, Schulz KM, Murakami MM, Love SA, Nicholson J, et al. Diagnosis of type 1 and type 2 myocardial infarction using a high-sensitivity cardiac troponin I assay with sex-specific 99th percentiles based on the third universal definition of myocardial infarction classification system. Clin Chem 2015; 61:657-63. doi: 10.1373/clinchem.2014.236638.

5. Fraga OR, Sandoval Y, Love SA, McKinney ZJ, Murakami MM, Smith SW, et al. Cardiac troponin testing is overused after the rule-in or rule-out of myocardial infarction. Clin Chem 2015; 61:436-8. doi: 10.1373/clinchem.2014.232694.

6. Nilsson S, Andersson A, Janzon M, Karlsson JE, Levin LÅ. Cost consequences of point-of-care troponin T testing in a Swedish primary health care setting. Scand J Prim Health Care 2014; 32:241-7. doi: 10.3109/02813432.2014.984901.

7. Bösner S, Haasenritter J, Becker A, Hani MA, Keller H, Sönnichsen AC, et al. Heart burn or angina? Differentiating gastrointestinal disease in primary care patients presenting with chest pain: A cross sectional diagnostic study. Int Arch Med 2009; 2:40. doi: 10.1186/1755-7682-2-40.

8. Roffi M, Patrono C, Collet JP, Mueller C, Valgimigli M, Andreotti F, et al. 2015 ESC guidelines for the management of acute coronary syndromes in patients presenting without persistent ST-segment elevation. Rev Esp Cardiol (Engl Ed) 2015; 68:1125. doi: 10.1016/j.rec.2015.10.009.

9. Love SA, McKinney ZJ, Sandoval Y, Smith SW, Kohler R, Murakami MM,et al. Electronic medical record-based performance improvement project to document and reduce excessive cardiac troponin testing. Clin Chem 2015; 61:498-504. doi: 10.1373/clinchem.2014.234310.

10. Thygesen K, Alpert JS, Jaffe AS, Simoons ML, Chaitman BR, White HD. Third universal definition of myocardial infarction. J Am Coll Cardiol 2012; 60:1581-98. doi: 10.1016/j. jacc.2012.08.001

11. Sandoval Y, Smith SW, Thordsen SE, Apple FS. Supply/demand type 2 myocardial infarction: Should we be paying more attention? J Am Coll Cardiol 2014; 63:2079-87. doi: 10.1016/j. jacc.2014.02.541.

12. Rehmani R, Amanullah S. Analysis of blood tests in the emergency department of a tertiary care hospital. Postgrad Med J 1999; 75:662-6. doi: 10.1136/pgmj.75.889.662.

13. Edwards B, Washington I, Pretlow L, Passmore G, Dias I, Wise S. Sequential assessment of troponin in the diagnosis of myocardial infarction. Clin Lab Sci 2013; 26:95-9.

14. Kalim S, Nazir S, Khan ZU. High sensitivity troponin T: An audit of implementation of its protocol in a district general hospital. J Ayub Med Coll Abbottabad 2013; 25:9-11. 
15. Rajappan K, Murphy E, Amber V, Meakin F, Muller B, Fox KF et al. Usage of troponin in the real world: A lesson for the introduction of biochemical assays. QJM 2005; 98:337-42. doi: 10.1093/qjmed/hci052.

16. Groarke JD, Browne L, Margey R, McCann HA, Blake GI, Sugrue DD, et al. A multicentre analysis of troponin use in clinical practice. Ir J Med Sci 2013; 182:185-90. doi: 10.1007/ s11845-012-0853-2.

17. Yiadom MY, Jarolim P, Jenkins C, Melanson SE, Conrad M, Kosowsky JM. Diagnostic implications of an elevated troponin in the emergency department. Dis Markers 2015; 2015:157812. doi: $10.1155 / 2015 / 157812$

18. Ebrahimi M, Mirhaghi A, Mazlom R, Heydari A, Nassehi A, Jafari $M$. The role descriptions of triage nurse in emergency department: A Delphi study. Scientifica (Cairo) 2016; 2016:5269815. doi: 10.1155/2016/5269815.
19. Andersson AK, Omberg M, Svedlund $M$. Triage in the emergency department: A qualitative study of the factors which nurses consider when making decisions. Nurs Crit Care 2006; 11:136-45. doi: 10.1111/j.1362-1017.2006.00162.x.

20. Holroyd BR, Bullard MJ, Latoszek K, Gordon D, Allen S, Tam S, et al. Impact of a triage liaison physician on emergency department overcrowding and throughput: A randomized controlled trial. Acad Emerg Med 2007; 14:702-8. doi: 10.11 97/j.aem.2007.04.018.

21. Seaberg DC, MacLeod BA. Correlation between triage nurse and physician ordering of ED tests. Am J Emerg Med 1998; 16:8-11. doi: 10.1016/S0735-6757(98)90057-2 